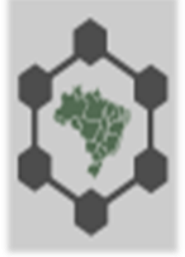

http://dx.doi.org/10.5935/1981-2965.20140034

Artigo Cientifico

http://www.higieneanimal.ufc.br

Características qualitativas de carcaças de cordeiros mestiços santa inês $x$ pantaneiro terminados em pastagem recebendo suplementação

Fabrício Eugênio Araújo ${ }^{1}$, Amorésio Souza Silva Filho ${ }^{2 *}$, Claudio Jonasson Mousquer ${ }^{2}$, Marcos Antônio de Oliveira ${ }^{3}$, Alexandre Agostinho Mexia ${ }^{4}$, Luiz Juliano Valério Geron ${ }^{4}$

Resumo: A ovinocultura está presente praticamente em todos os continentes, a ampla difusão da espécie se deve principalmente a seu poder de adaptação a diferentes climas, relevos e vegetações. Ela se caracteriza pelo seu aspecto econômico e sua facilidade de criação para a subsistência das famílias de zonas rurais. O experimento foi realizado no Sitio Segredinho no município de Pontes e Lacerda, Mato Grosso. Utilizando 18 cordeiros machos não castrados, animais mestiços Santa Inês x Pantaneiros, com idade média de 90 dias, sendo criados até o período de desmama de forma semelhante, com peso vivo (PV) médio inicial de $16,72 \mathrm{~kg}$. Os animais foram distribuídos em 3 tratamentos, sendo: PS0\% - animais criados em pastagem de Brachiaria brizantha cv. Marandú durante o dia sem fornecimento de suplementação; PS1\% - animais criados na mesma pastagem e recebendo suplementação a $1 \%$ do PV e PS2\% - 2\% do PV. Animais suplementados apresentam maior concentração de extrato etéreo em sua composição, e comparando o aumento das doses de concentrado essa concentração aumenta. Isso faz com que gere maior aporte de nutrientes e energia promovido pela suplementação, acarretando diferenças no extrato etéreo da carne dos ovinos. Para a AOL houve significância, sendo maior nos cordeiros que receberam suplementação a $2 \%$, em relação os que não receberam suplementação, sendo que o nível $1 \%$ não diferiu dos demais. Essa maior área de lombo possibilita maiores proporções de músculo, devido ao maior nível de suplementação correspondente a PS2\%. Logo, indica-se o uso deste nível de suplementação ao se pensar no fornecimento de produto de qualidade superior ao mercado consumidor.

Palavras-chave: Qualidade de carcaça; terminação á pasto; zootecnia. 


\title{
Qualitative characteristics of cases of lambs crossbreds santa ines x pantaneiro finished on pasture and supplementation
}

\begin{abstract}
The sheep industry is present in virtually all continents, the wide diffusion of species is mainly due to its ability to adapt to different climates, reliefs and vegetations. It is characterized by its economics and its ease of creation to the livelihoods of rural households. The experiment was conducted at Sitio Little Secret in the city of Pontes e Lacerda, Mato Grosso. Using 18 male not castrated, crossbred Santa Ines x Pantaneiro, with an average age of 90 days, being created until the period of weaning similarly, with average initial body weight (BW) of $16.72 \mathrm{~kg}$. The animals were divided into 3 treatments being: PS0\% - animals raised on Brachiaria brizantha. Marandú during the day without providing supplementation; \% PS1 - animals raised in the same pasture and receiving supplementation at $1 \%$ of BW and PS2\% - 2\% of BW. Supplemented animals have higher concentrations of ether extract in its composition, and comparing the increase in concentrated doses it increases. This causes generate higher nutrient and energy supplementation promoted by, causing differences in the ether extract of the flesh of sheep. For AOL was significant, being higher in lambs supplemented at $2 \%$ over those not receiving supplementation, and the $1 \%$ level did not differ from the others. This enables larger back area larger proportions of muscle, due to the higher level of supplementation corresponding to PS2\%. Then indicates the use of this level of supplementation when thinking in providing superior product quality to the consumer market.
\end{abstract}

Keywords: Carcass quality; will pasture finishing; Animal science

\footnotetext{
${ }^{1}$ Mestrando em Ciência Animal, Universidade Federal de Mato Grosso do Sul, Campus de Dourados-MS

${ }^{2}$ Mestrandos em Ciência Animal, Universidade Federal de Mato Grosso, Campus Cuiabá-MT

${ }^{3}$ Mestrando em Aquicultura no Centro de Aquicultura da UNESP

${ }^{4}$ Professor do Departamento de Zootecnia da Universidade do Estado de Mato Grosso

(UNEMAT), Rodovia 174, km 209, caixa postal 181, Pontes e Lacerda - MT
}

Autor para correspondência. E. Mail: *amoresio zootecnista@hotmail.com

Recebido em 15/03/2014. Aceito em 18/05/2014 


\section{Introdução}

A ovinocultura esta em grande desenvolvimento diante do mercado brasileiro, devido, a aceitação do produto final frente ao consumidor, e ao rápido crescimento com maior rotatividade financeira e facilidade de criação para o produtor. Isso se deve ao trabalho de pessoas qualificadas, que ao utilizar de técnicas de produção, obtenham carne ovina com melhores parâmetros de qualidade comparados com as carnes de outras espécies, tendo menor espessura de gordura e maior proporção de músculo.

Esse fato, aliado às características dos ovinos de serem animais dóceis, manejados facilmente e que não necessitam de áreas extensas, quando comparados com os bovinos, vem despertando o interesse de produtores rurais detentores de pequenas áreas, a desenvolver a criação de ovinos como alternativa econômica em suas propriedades, principalmente quando próximas a centros consumidores (VECHI, 2014).

A ovinocultura está presente praticamente em todos os continentes, a ampla difusão da espécie se deve principalmente a seu poder de adaptação a diferentes climas, relevos e vegetações. Ela se caracteriza pelo seu aspecto econômico e sua facilidade de criação para a subsistência das famílias de zonas rurais (VIANA, 2008). O mercado é bastante promissor e, segundo SIMPLÍCIO (2001) existe um amplo mercado a ser conquistado, o que dependerá fundamentalmente da organização e gestão da cadeia produtiva, o que permearia o desenvolvimento e crescimento ordenado do setor de produção.

De acordo com o IBGE (2012) o Brasil detém de um rebanho de ovinos em torno de 16,789 milhões de animais, podendo o rebanho ovino chegar a 3,0 bilhões em 2050 com peso médio de 17 $\mathrm{Kg}$. As maiores participações do efetivo de rebanho ocorreram no Nordeste do País 
$(55,5 \%)$, com destaque na Bahia $(16,8 \%)$ e Ceará (12,3\%). No Sul do País, houve a concentração de $30,0 \%$ da criação de ovinos, sendo que $24,4 \%$ do efetivo nacional estava no Rio Grande do Sul. Para que o rebanho continue crescendo é preciso enfaziar o consumo da carne ovina pela população, sendo o consumo baixo é preciso popularizar o uso da carne ovina mediante a divulgação de receitas e formas de utilização no dia-a-dia das pessoas, como, também, fazer promoções de preço, estímulo popular em supermercados (SANTOS, 2003) e variação de cortes.

Dentro do desenvolvimento dos ovinos é visto que a carcaça é o elemento mais importante do animal, porque nela está contida a porção comestível. Em virtude disso, devem ser comparadas suas características de qualidade para que seja possível detectar as diferenças existentes entre animais, identificando aqueles que produzam melhores carcaças (CARVALHO, 1998).
Estima-se um crescimento anual de $2,1 \%$ na produção de carne ovina durante o período de 2005 a 2014, registrando-se essa elevação em países em desenvolvimento (VIANA, 2008).

Para que isso seja alcançado além, do conhecimento sobre crescimento e desenvolvimento dos ovinos, é fundamental conhecer as características qualitativas de carcaças, visando melhorar a qualidade do produto final (JESUS, 2007).

O termo qualidade esta sendo mais estudado por ser um conceito bastante amplo e complexo, pois está relacionado com todas as etapas da cadeia agroindustrial, desde o nascimento do animal até o preparo para consumo final da carne in natura e dos produtos cárneos processados (BRESSAN \& FERRÃO, 2003). Assim, torna-se importante o conhecimento das definições desses caracteres qualitativos, já que os compradores fazem sua escolha de consumo baseado nesse parâmetro de 
qualidade, oportunidade esta, ainda, passível de agregação de valor ao produto final (SILVA et al., 2008).

É preciso então obter carcaças com boa conformação aliadas a qualidade de carne, justificando um produto apreciado aos diversos consumidores, levando ao aumento de consumo e, como consequência aumento da criação e do rebanho nacional. Objetivou-se com este trabalho analisar as características qualitativas da carne dos cordeiros mestiços Santa Inês X Pantaneiros, suplementados a pasto.

\section{Material e Métodos}

O experimento foi realizado no Sitio Segredinho, de propriedade do $\mathrm{Sr}$. Ariovaldo Nunes de Oliveira, no município de Pontes e Lacerda, Mato Grosso. Foram utilizados 18 cordeiros machos não castrados, animais mestiços Santa Inês $\mathrm{x}$ Pantaneiros devidamente identificados, com idade média de 90 dias, sendo criados até o período de desmama de forma semelhante, e o peso vivo (PV) médio inicial foi de $16,72 \mathrm{Kg}$.

Os animais foram distribuídos em 3 tratamentos variando entre eles o nível de suplementação, sendo: PS0\% - animais criados em pastagem de Brachiaria brizantha cv. Marandú durante o dia sem fornecimento de suplementação; PS1\% animais criados em pastagem de Brachiaria brizantha cv. Marandú durante o dia recebendo suplementação a $1 \%$ do PV nas instalações e PS2\% - animais criados em pastagem de Brachiaria brizantha cv. Marandú durante o dia recebendo suplementação a $2 \%$ do PV nas instalações.

Durante o período experimental (84 dias), os animais permaneceram juntos em um piquete de seis hectares (pastejo contínuo), com pastagem de Brachiaria brizantha cv. Marandú. Os animais tinham acesso diariamente à pastagem das 8:00 às 18:00 horas, quando eram recolhidos para instalações cobertas com piso de terra batida. $\mathrm{O}$ aprisco continha três repartições 
Araujo et al., Revista Brasileira de Higiene e Sanidade Animal (v.8, n.2) p. 263 - 278, abr - jun (2014)

para separação dos tratamentos sendo equipado com comedouros e bebedouros.

Foram recolhidas amostras pelo método de dupla amostragem (WILM et al,. 1944) do pasto de Brachiaria brizantha cv. Marandú em três períodos (Fevereiro, Março e Abril) no ano de 2010. Posteriormente o material foi separado em folhas, colmos e material senescente, sendo utilizado somente as folhas para análise de proteína bruta $(\mathrm{PB})$, fibra em detergem ácido (FDA) e fibra em detergente neutro (FDN), segundo metodologia de Campos et al. (2004), no Laboratório de Análises de Alimentos, da Universidade do Estado de Mato Grosso (UNEMAT), Campus Universitário de Pontes e Lacerda/MT. Os resultados da composição química das folhas da Brachiaria brizantha cv. Marandú estão demonstrados na Tabela 1.

Tabela 1. Composição química da Brachiaria brizantha cv. Marandú em Proteína Bruta (PB), Fibra em Detergente Ácido (FDA), Fibra em Detergente Neutro (FDN).

\begin{tabular}{lccc}
\hline Corte & PB & FDN & FDA \\
Fevereiro & 9,51 & 66,30 & 42,45 \\
Março & 9,36 & 66,93 & 32,68 \\
Abril & 8,82 & 65,96 & 31,83 \\
\hline
\end{tabular}

O suplemento utilizado nos tratamentos PS1\% e PS2\% foi à base de grão de milho moído (60\%), farelo de soja (20\%) e torta de girassol (20\%), tendo em sua composição $19,2 \%$ de PB e 86,4 de NDT.

Os animais foram pesados semanalmente para controle do ganho médio diário (GMD) e ajuste do suplemento.
Foi fornecido sal mineral a uma proporção de 12g/animal (Santallo et al., 2006) e água a vontade aos animais durante todo período experimental. Ainda, ao início os cordeiros receberam aplicação de anti-helmíntico conforme indicação do fabricante.

Ao completar 84 dias da fase experimental os animais passaram por um jejum prévio de 13 horas, e foram pesados 
por balança digital, também foi avaliado o escore de condição corporal dos animais, em seguida foram abatidos e eviscerados e pesado as carcaças, obtendo-se o peso da carcaça quente e após 24 h em câmara refrigerada a $4^{\circ} \mathrm{C}$, as carcaças foram novamente pesadas, para obtenção do peso da carcaça fria, calculando-se a percentagem de perda de peso por resfriamento (PR).

$\mathrm{O} \mathrm{pH}$ foi realizados em duas etapas, na secção no músculo Longissimus dorsi, na região lombar do lado esquerdo da carcaça sendo o pH0 horas no momento do abate e o pH24 horas depois que a carcaça foi refrigerada.

No Longissimus lumborum (entre a última vértebra torácica e a primeira lombar, no corte denominado lombo), tomou-se a área transversal em transparência e, posteriormente foi determinada a área de olho de lombo, através do programa computacional AUTOCAD®, sendo scaniado a transparência para ser jogada no programa onde foi estimado sua área.

Ainda no mesmo músculo (Figura 1), utilizando-se paquímetro, foram feitas quatro medidas: Medida A- comprimento maior do músculo Longissimus dorsi, perpendicular ao eixo ou medida $\mathrm{B}$; Medida B- comprimento menor do músculo Longissimus dorsi: é a profundidade máxima do mesmo; Medida C- espessura de gordura sobre o músculo Longissimus dorsi: é a espessura da gordura de cobertura sobre a secção transversal do referido músculo, à continuação do eixo B.

Amostras retiradas do lombo através de corte transversal foram separadas individualmente e dissecados, para determinação das proporções de músculo (M), gordura (G) e osso (O). Apenas a proporção de músculo foi submetidas às análises de Cinzas, Proteína Bruta e Extrato Etéreo após serem maceradas, segundo metodologia descrita por CAMPOS et al. (2004). 
Para realizar as análises estatísticas, foi utilizado o programa Sisvar através do
Teste de Tukey com nível de significância menor que $5 \%$.

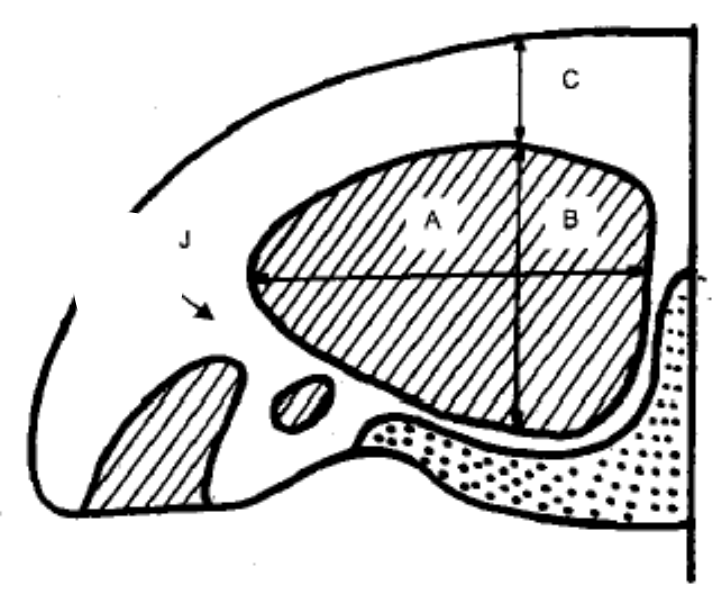

Figura 1. Mensurações realizadas no músculo longissimus lumborum das cordeiras. A- comprimento maior, B- comprimento menor e C-espessura de gordura. Fonte: Mexia (2005).

\section{Resultados e Discussão}

As médias e o coeficiente de variação para a medida A e B do lombo, a área de olho de lombo (AOL) e a espessura de gordura (EG), estão demonstrados na Tabela 2.

Tabela 2. Médias e coeficiente de variação para o comprimento maior do lombo, comprimento menor do lombo, área de olho de lombo (AOL) e espessura de gordura.

\begin{tabular}{lcccc}
\hline & \multicolumn{3}{c}{ Tratamento } & CV (\%) \\
\cline { 2 - 4 } Variáveis & P\% & PS1\% & PS2\% & \\
\hline Medida A mm & $39,412 \mathrm{a}$ & $44,998 \mathrm{a}$ & $47,220 \mathrm{a}$ & 17,24 \\
Medida B mm & $18,868 \mathrm{a}$ & $22,218 \mathrm{a}$ & $23,182 \mathrm{a}$ & 16,66 \\
AOL cm & $5,598 \mathrm{~b}$ & $7,222 \mathrm{ab}$ & $9,255 \mathrm{a}$ & 20,45 \\
Espessura de gordura mm & $0,143 \mathrm{a}$ & $0,153 \mathrm{a}$ & $0,300 \mathrm{a}$ & 60,37 \\
\hline
\end{tabular}

Médias seguidas de letras minúsculas nas linhas diferem entre si pelo Teste de Tukey a 5\%

Podemos observar que não houve

diferença significativa para a medida A e B do lombo e nem para EG $(\mathrm{P}>0,05)$, já para a AOL houve significância, sendo maior nos cordeiros que receberam suplementação a $2 \%$, em relação os que 
não receberam suplementação, sendo que o nível $1 \%$ não diferiu dos demais. Essa maior área de lombo possibilita maiores proporções de músculo, devido ao maior nível de suplementação correspondente a PS2\%.

Essa mudança podem ocorrer na carcaça devido á fatores intrínsecos relacionados ao próprio animal: idade, sexo, base genética, morfologia, peso ao nascimento e peso ao abate; por fatores extrínsecos: alimentação, manejo, e homogeneidade das pesagens e realização de pré jejum - abate e fatores relacionados com a própria carcaça: peso, comprimento, compacidade, conformação e acabamento também influenciam no rendimento. Á diferença na espessura de gordura sofre efeito de alguns fatores, onde cordeiros abatidos com $35,57 \mathrm{~kg}$ apresentam valores superiores àqueles abatidos ao desmame (20,93 kg) (PÉREZ \& CARVALHO, 2011; SILVA \& PIRES, 2000).

RIBEIRO et al. (2005) objetivaram avaliar os pesos e rendimentos da carcaça e características do lombo (longissimus dorsi) de cordeiros criados nos seguintes sistemas de terminação: (1) cordeiros desmamados aos 40 dias e mantidos em pastagem de azevém anual até o abate; (2) cordeiros mantidos com suas mães na mesma pastagem até o abate; (3) cordeiros mantidos com suas mães na mesma pastagem, porém a partir dos 40 dias, houve acesso exclusivo dos cordeiros à suplementação com concentrado, em $1 \%$ do peso vivo (“creep feeding"); (4) cordeiros desmamados aos 40 dias e confinados, recebendo silagem de milho e concentrado "ad libitum”. Os cordeiros machos foram abatidos ao atingirem o peso de $32 \mathrm{~kg}$ após jejum. Observaram que área de olho de lombo, largura máxima e mínima do lombo não foram afetas pelos diferentes tratamentos. Já para a variável espessura mínima e máxima de gordura os cordeiros desmamados apresentaram valores inferiores comparados aos demais. PILAR et al. (2005) ao utilizarem 48 cordeiros machos não castrados, sendo 24 
da raça Merino Australiano e 24 cruzados

da raça Ilê de France x Merino Australiano

terminados em confinamento e abatidos

com $15,25,35$ e $45 \mathrm{~kg}$, observaram que

em todas as faixas de peso, os cordeiros

cruzados mostraram maior AOL que os

Merinos. Na faixa de $15 \mathrm{~kg}$ não houve

diferença entre os genótipos da espessura de gordura de cobertura, aos 25 e $35 \mathrm{~kg}$ os cordeiros cruzados tiveram menor espessura e, aos $45 \mathrm{~kg}$, maior espessura que os Merinos.

As médias e o coeficiente de variação para proteína bruta $(\mathrm{PB})$, extrato etéreo (EE), cinzas e pH0 e pH24, estão demonstrados na Tabela 3.

Tabela 3. Médias e coeficiente de variação para Proteína bruta (PB), Extrato etéreo (EE), Mineral e pH 0 e pH 24 da carne de cordeiro não castrados mestiços Santa Inês X Pantaneiros

\begin{tabular}{lcccc}
\hline & \multicolumn{3}{c}{ Tratamento } & CV (\%) \\
\cline { 2 - 3 } Variável & PS0\% & PS1\% & PS2\% & \\
\hline \% PB & $24,080 \mathrm{a}$ & $24,345 \mathrm{Aa}$ & $23,708 \mathrm{a}$ & 4,69 \\
$\%$ EE & $2,022 \mathrm{~b}$ & $2,752 \mathrm{ab}$ & $3,675 \mathrm{a}$ & 31,04 \\
\% MINERAL & $0,993 \mathrm{a}$ & $1,070 \mathrm{a}$ & $1,065 \mathrm{a}$ & 12,02 \\
Ph 0 & $6,477 \mathrm{a}$ & $6,639 \mathrm{a}$ & $6,417 \mathrm{a}$ & 3,32 \\
Ph 24 & $5,248 \mathrm{a}$ & $5,303 \mathrm{a}$ & $5,222 \mathrm{a}$ & 3,97 \\
\hline
\end{tabular}

Médias seguidas de letras minúsculas nas linhas diferem entre si pelo Teste de Tukey a 5\%

Não houve diferença significativa para $\mathrm{PB}$, cinzas e $\mathrm{pH} 0$ e $\mathrm{pH} 24$ entre os tratamentos. O EE teve efeito significativo, sendo maior para os que receberam suplementação a PS2\% em relação aos que receberam PS0\%, sendo que o nível PS1\% não diferiu dos demais.

Animais suplementados apresentam maior concentração de extrato etéreo em sua composição, e comparando o aumento das doses de concentrado essa concentração aumenta. Isso faz com que gere maior aporte de nutrientes e energia promovido pela suplementação, acarretando diferenças no extrato etéreo da carne dos ovinos (SOUZA et al., 2010).

E as carcaças por serem resultados de um processo biológico individual sobre o qual interferem fatores genéticos, ecológicos e de manejo, diferindo entre si 
por suas características quantitativas e qualitativas, susceptíveis de identificação, sofreram poucas alterações em sua composição química devido um destes fatores (OSÓRIO \& OSÓRIO, 2001).

SANTOS et al. (2009), ao utilizarem 24 ovinos castrados com PV médio de $15,8 \mathrm{~kg}$ distribuídos em tratamentos com três níveis de suplementação com concentrado $(0 ; 1,0$ e $1,5 \%$ do PV) analisaram a composição tecidual e química da perna e do lombo, perceberam que a suplementação influenciou os percentuais de cinzas, proteína bruta e gordura do lombo e da perna. A suplementação melhora o rendimento muscular e a composição química do lombo e da perna de ovinos Santa Inês terminados em pastagem nativa.
LAGE et al. (2009) ao utilizar 30 machos não castrados, com peso médio inicial de $20 \mathrm{Kg}$, recebendo níveis de inclusão de glicerina bruta $(0$ 3, 6, 9 e $12 \%$ na MS) em substituição ao milho, observaram que não houve efeito dos níveis de glicerina para as características $\mathrm{pH}$ (inicial e final).

As médias e o coeficiente de variação para proporção de osso, músculo e gordura estão demonstrados na Tabela 4. Não houve diferença significativa (P $>0,05)$ para nenhuma das variáveis estudadas, verifica-se que o nível de suplementação não alterando a gordura, principal parâmetro para aceitação da carne, é de grande importância, pois melhora o rendimento da carcaça.

Tabela 4. Médias e coeficiente de variação para proporção de osso, músculo e gordura em cordeiros suplementados a pasto.

\begin{tabular}{lcccc}
\hline & \multicolumn{3}{c}{ Tratamento } & CV (\%) \\
\cline { 2 - 4 } Variável & PS0\%\% & PS1\% & PS2\% & \\
\hline \% Osso & $29,468 \mathrm{a}$ & $28,895 \mathrm{a}$ & $25,448 \mathrm{a}$ & 10,38 \\
\% Músculo & $65,612 \mathrm{a}$ & $64,985 \mathrm{a}$ & $67,835 \mathrm{a}$ & 4,85 \\
\% Gordura & $4,920 \mathrm{a}$ & $6,123 \mathrm{a}$ & $6,715 \mathrm{a}$ & 43,84 \\
\hline
\end{tabular}

Médias seguidas de letras minúsculas nas linhas diferem entre si pelo Teste de Tukey a 5\% 
De acordo com a idade e o sexo do animal, observamos na carcaça diferentes proporções de osso, músculo e gordura. Para maiores idades, há diminuição da porcentagem de músculo e aumento na gordura, tendo os ossos menores variações em sua amplitude (ROÇA, 2011).

E quando suplementados apresentam maior crescimento de músculo, como visto no devido experimento que não houve diferença, a proporção de músculo aumentou com a maior percentagem de suplementação. É visto que a gordura apresenta crescimento tecidual lento, e o tecido ósseo crescimento precoce, devido ao desenvolvimento progressivo em função dos diferentes níveis de suplementação e maior atividade física dos animais não suplementados, o que resulta em maiores exigências nutricionais (DANTAS et al., 2008; ROSA et al., 2002; ANIMUT et al., 2005; SANTOS, 2006).

Ao utilizar cordeiros terminados a pasto de azevém anual com diferentes níveis de suplementação (sem suplementação, $1 \%, 2 \%$ e ad libitum) e abatidos com $32 \mathrm{Kg}$, Fernandes et al. (2007), observaram que não houve efeito dos tratamentos sobre o peso total, peso de músculo, gordura subcutânea, osso e outros componentes do lombo direito, mostrando que a suplementação não interferiu nestas variáveis.

\section{Conclusão}

Cordeiros mestiços Santa Inês X Pantaneiros terminados a pasto, recebendo 2\% do PV em suplemento, apresentam maior área de olho de lombo. Sendo assim, como esta medida esta atrelada a musculosidade da carcaça do animal, é indicada o uso deste ao se pensar no fornecimento de produto de qualidade superior ao mercado consumidor.

\section{Referências Bibliográficas}

ANIMUT, G.; GOETSCH, A. L.; AIKEN, G. E.; PUCHALA, R.; DETWEILER G.; KREHBIEL, C. R.; MERKEL, R. C.; SAHLU, T.; DAWSOND, L. J.; JOHNSON, Z. B.; GIPSON, T. A. Grazing behavior and energy expenditure by sheep 
and goats co-grazing grass/forb pastures at three stocking rates. Small Ruminants

Research, Amsterdam, v. 59, p.191-201, 2005.

BRESSAN, M.C.; FERRÃO. Qualidade da Carne Bovina do Frigorífico ao Consumidor. In: SEMANA DE ZOOTECNIA, 2003, Pontes e Lacerda. Anais... Pontes e Lacerda: Universidade Estadual do Mato Grosso, UNEMAT. Campus Universitário de Pontes e LacerdaMT, 2003. 1. CD-ROOM.

CAMPOS, F.P.; NUSSIO, C.M.B.; NUSSIO, L.G. Métodos de análise de alimento. Piracicaba: FEALQ, 2004, 135 p.

CARVALHO, S. Desempenho, composição corporal e exigências nutricionais de cordeiros machos inteiros, machos castrados e fêmeas alimentadas em confinamento. 1998. 102p. Dissertação (Mestrado em Zootecnia) - Universidade Federal de Santa Maria, Santa Maria, 1998.
DANTAS, A.F.; PEREIRA FILHO, J.M.; SILVA, A.M. de A; et al. Característica da carcaça de ovinos Santa Inês terminados em pastejo e submetidos a diferentes níveis de suplementação. Ciência Agrotecnica, Lavras, v. 32, n. 4, p. 1280 - 1286, 2008. FERNANDES, M.A.M.; MONTEIRO, A.L.G.; POLI, C.H.E.C.; et al. Medidas e composição tecidual do lombo de cordeiros terminados em pastagem de azevém anual com diferentes níveis de suplementação. In: REUNIAÕ ANUAL DA SOCIEDADE BRASILEIRA DE ZOOTECNIA, $44^{\circ}$, 2007, Jaboticabal-SP. Anais... JaboticabalSP: UNESP, 2007, p. 1-3.

IBGE - Instituto Brasileiro de Geografica e Estatística. Comentários: Panorama da pecuária nacional em 2012. 2012. Disponível em: <ftp://ftp.ibge.gov.br/Producao_Pecuaria/P roducao_da_Pecuaria_Municipal/2012/co mentarios.pdf $>$. Acessado em 24 de abril de 2014. 
JESUS, T.I. Considerações sobre carcaças ovinas e utilização da ultrasonografia como ferramenta na avaliação de características de carcaças de ovinos da raça Santa Inês mantidos em confinamento para terminação. 2007. 61p. Monografia (Graduação em Medicina Veterinária), Universidade Metodista de São Paulo, São Bernardo do Campo, 2007.

LAGE， J.F.; PAULINHO, P.V.R.; PEREIRA, L.G.R.; et al. pH e força de cisalhamento da carne de cordeiros alimentados com glicerina bruta na fase de terminação. In: ZOOTEC, 2009, Águas de Lindóia-SP. Anais... Águas de Lindóia-SP: FZEA/USP-ABZ, 2009, p. 1-4.

MEXIA, A. A. Características qualitativas de carcaças de cordeiras terminadas em confinamento ou pastagem mais suplementação. 2005. 87 p. Tese (Doutorado em Zootecnia), Produção animal, Universidade Estadual de Maringá, Maringá-PR, 2005.
OSÓRIO, J.C.S.; OSÓRIO, M.T.N. Sistemas de avaliação de carcaças no Brasil. In: SIMPÓSIO MINEIRO DE OVINOCULTURA, 1., 2001, Lavras, MG. Anais... Lavras: UFLA, p. 157-196, 2001. PÉREZ, J.R.O.; CARVALHO, P.A. Considerações sobre Carcaças Ovinas. Boletim Agropecuário, Lavras - MG, 2011. Disponível em: <http://www.editora.ufla.br/site/_adm/uplo ad/boletim/bol_61.pdf>. Acesso em: 05 de maio de 2011.

PILAR, R de.C.; PÉREZ, J.R.O.; NUNES, F.M. Rendimentos e características quantitativas de carcaças em cordeiros Merinos Australiano e cruza Ilê de France x Merinos Australiano. Revista brasileira de Agrociência, Pelotas, v. 11, n. 3, p. 251-359, 2005.

ROÇA, R de. O. Sistema de produção $x$ Qualidade da carne ovina. Botucatu-SP, 2011. Disponível em: < http://dgta.fca.unesp.br/carnes/Alunos\%20 PG/Zootecnia/Roca328.pdf>. Acessado em 08 de junho de 2011. 
ROSA, G. T.; PIRES, C. P.; SILVA, J. H. S.; MULLER, L. Crescimento de osso músculos e gordura dos cortes da carcaça de cordeiros e cordeiras em diferentes métodos de alimentação. Revista Brasileira de Zootecnia, Viçosa, v. 31, n. 6, p. 2283-2289, 2002.

SANTELLO, G.A.; MACEDO, F. de A.F.; MEXIA, A.A. et al. Características de carcaça e análise do custo de sismeas de prodição de cordeiras 1/2 Dorset Santa Inês. Revista Brasileira de Zootecnia, Viçosa, v. 35, n. 4, p. 1852-1859, 2006.

SANTOS, E. M. Exigências nutricionais de energia e proteína e estimativa de consumo de ovinos em pastejo no semiárido. 2006. 50 f. Dissertação (Mestrado em Zootecnia) Universidade Federal de Campina Grande, Patos, 2006.

SANTOS, J.R.S do.; PEREIRA FILHO, J.M.; SILVA, A.M.A.; et al. Composição tecidual e química de cordeiros Santa Inês terminados em pastagem nativa com suplementação. Revista Brasileira de
Zootecnia, Viçosa, v. 38, n. 12, p. 24992505, 2009.

SANTOS, M.B. Carne de ovino é um grande negócio: abaixo "o churrasco". $\mathbf{O}$ Berro, Uberaba, n. 58, p. 26 - 33, set. 2003.

SILVA, L.F da.; PIRES, C.C. Avaliações quantitativas e predição das proporções de osso, músculo e gordura da carcaça de ovinos. Revista Brasileira de Zootecnia, v. 29, n. $4,2000$.

SILVA, N.V da.; SILVA, J.H.V da.; COELHO, M de.S.; et al. Características de carcaça e carne ovina: uma abordagem das variáveis metodológicas e fatores de influência. Acta Veterinaria Brasilica, Paraíba, v. 2, n. 4, p. 103-110, 2008. SIMPLÍCIO, A.A. A caprino-ovinocultura na visão do agronegócio. Revista Conselho Federal de Medicina Veterinária,. Brasília/DF, n. 24, ano VII, p. 15-18, set/out/dez 2001. 
SOUZA, R.A.; VOLTOLINI, T.V.; $\quad$ WILM, H.G.; COSTELO, O.F.; KLIPPLE. PEREIRA, L.G.R.; MORAES, S.A de.; G.E. Estimating forage yilo by the double MANERA, D.B.; ARAÚJO, G.G.L de. sampling method. Jornal American of Desempenho produtivo e parâmetros de Agronomic, v. 36, n. 1, p. 194-203, 1944. carcaça de cordeiros mantidos em pastos irrigados e suplementados com doses crescentes de concentrado. Acta Scientiarum. Animal Sciences, Maringá, v. 32, n. 3, p. 323-329, 2010.

VECHI, J.B. A. Criação de ovinos em mato grosso: Uma alternativa para o ingresso de pequenos e médios produtores rurais na atividade. Mato Grosso.

Disponível em: <www.seder.mt.gov.br/.../A_c8e35ceb0ca8 142aaaff2f55be2c4114CRIACAO_OVIN OS_PROPOSTA_3.doc>. Acesso em: 24 de abril de 2014.

VIANA, J.G.A. Panorama geral da ovinocultura no mundo e no Brasil. Revista Ovinos, Porto Alegre, ano 4, $\mathrm{n}^{\mathrm{o}}$. 12, 2008, p. 1-9. 